\title{
GMR
}

\section{Differential gene expression in the peripheral blood of Chinese Sanhe cattle exposed to severe cold stress}

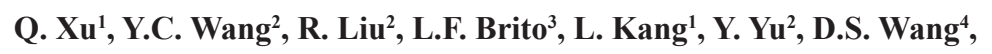 \\ H.J. Wu ${ }^{4}$ and A. Liu ${ }^{5}$ \\ ${ }^{1}$ Institute of Life Science and Biotechnology, Beijing Jiaotong University, \\ Beijing, China \\ ${ }^{2}$ Key Laboratory of Agricultural Animal Genetics and Breeding National Engineering, \\ Laboratory for Animal Breeding, College of Animal Science and Technology, \\ China Agricultural University, Beijing, China \\ ${ }^{3}$ Centre for Genetic Improvement of Livestock, Department of Animal Biosciences, \\ University of Guelph, Guelph, Ontario, Canada \\ ${ }^{4}$ Xiertala Cattle Breeding Farm, Hailaer Farm Buro, Hailaer, Inner Mongolia, \\ China ${ }^{5}$ Moguai Farm, Hailaer Farm Buro, Hailaer, Inner Mongolia, China \\ Corresponding author: Y.C. Wang \\ E-mail: wangyachun@cau.edu.cn
}

Genet. Mol. Res. 16 (2): gmr16029593

Received December 21, 2016

Accepted May 8, 2017

Published June 20, 2017

DOI http://dx.doi.org/10.4238/gmr16029593

Copyright $(2017$ The Authors. This is an open-access article distributed under the terms of the Creative Commons Attribution ShareAlike (CC BY-SA) 4.0 License.

\begin{abstract}
Livestock is an important food resource for the inhabitants of cold regions, such as northern Asia and alpine regions, where agriculture is limited. In these regions, cold stress largely affects livestock production, thereby reducing the productivity and survival of animals. Despite the importance of breeding cold-tolerant animals, few studies have investigated the effects of cold stress on cattle. Furthermore, whether severe cold stress alters gene expression or affects molecular genetic mechanisms remains unknown. Thus, we investigated gene expression changes in the peripheral blood samples
\end{abstract}

Genetics and Molecular Research 16 (2): gmr16029593 
of the Chinese Sanhe cattle exposed to severe cold. A total of 193 genes were found to exhibit significant alteration in expression $(\mathrm{P}<0.05$; fold change $>1.3$ ), with 107 genes showing upregulation and 86 showing downregulation after cold exposure. The differences in the expression of 10 selected genes were further validated by real-time qRT-PCR. Further analyses showed that these differentially expressed genes (DEGs) were predominantly associated with important biological pathways and gene networks, such as lipid metabolism and cell death and survival, which are potentially associated with severe cold-stress resistance. Identification and description of these cold stress-induced DEGs might lead to the discovery of novel blood biomarkers that could be used to assess cold-stress resistance in cattle. To our knowledge, this is the first genomic evidence of differences in the transcript expression pattern in cattle exposed to severe cold stress. Our findings provide insights on the potential molecular mechanisms underlying cold-stress response in cattle.

Key words: Severe cold stress; Sanhe cattle; Gene expression; Genome microarray; Temperature stress

\section{INTRODUCTION}

Livestock production is an important food resource for the inhabitants of cold regions, such as northern Asia and alpine regions, where agriculture is limited. In developing areas, owing to the lack of financial and material resources for animal housing, animals are raised outdoors throughout their lives or semi-housed in cowsheds. Temperature stress is a major factor that can negatively affect the growth and production of all livestock species. Examples of factors that lead to stress during the winter season are cold, wind, snow, rain, and mud, which can alter the maintenance energy requirements of various livestock species. Under severe cold stress conditions, some alterations in the body functions of animals are muscle shivering to increased heart rate, deeper breathing, and increased metabolic rate, which consequently result in increased nutrient and energy requirements. The assumed range of neutral temperatures for dairy cattle is from $-5^{\circ}$ to $25^{\circ} \mathrm{C}$, and milk production has been shown to be affected in cows kept in environments with temperatures below $-0.5^{\circ} \mathrm{C}$ (West, 2003). Exposure of dairy cows to cold stress can also result in increased plasma concentration of free fatty acids and decreased milk yield (Broucek et al., 1991). Under moderate cold stress, the milk yield of animals with an average milk yield of 21.6 $\mathrm{kg}$ was reduced by approximately $2 \mathrm{~kg}$, showing a strong correlation between milk production and the WIND Chill Temperature index (Angrecka and Herbut, 2015). Furthermore, Broucek et al. (1991) recorded a 2-kg decrease in the milk yield of cows with an average milk yield of $15 \mathrm{~kg}$ when temperatures were below $-10^{\circ} \mathrm{C}$ (Broucek et al., 1991). Furthermore, Azzam et al., (1993) reported that cold stress is an important cause of calf mortality in the United States of America. These losses resulted in an estimated $\$ 38$ million reduction in the income from the cattle industry (Azzam et al., 1993). Chebel et al. (2007)reported that an exposure to cold stress was associated with reduced conception rates and increased fetal loss. Heifers exposed to cold stress around the initiation of the breeding program, when inseminated, became pregnant at a slower rate than those not exposed to extreme air temperatures (Chebel et al., 2007).

Genetics and Molecular Research 16 (2): gmr16029593 
Studies conducted on the effects of cold stress emphasize on the response and productivity of cattle and the ways to handle them under unfavorable environmental conditions. Though the molecular mechanisms underlying heat-stress response have been well studied, very little information is available regarding the molecular mechanisms of cold-stress response or alterations in gene expression before and after severe cold stress (Collier et al., 2008; Hu et al., 2016). Kumar et al. (2015) reported the up-regulation of HSPA1A, HSPA1B, HSP60, and HSP10 expression in Murrah buffalo, Tharparkar, and Sahiwal cattle during the winter season compared to spring. To our knowledge, a global gene expression profile of cattle in response to cold stress has not been reported so far, although it has been investigated in other animal species or cell models (e.g., Sonna et al., 2010; Chen et al., 2012; Shore et al., 2013).

Cheng (1984) and Wu et al. (2012) have reported that the Chinese Sanhe cattle is a dual-purpose (milk and meat) breed that originated as a result of the long-term selection (over one century) and crossbreeding between the native Mongolian cattle and exotic breeds, such as Simmental and Shorthorn, in the grasslands of northeastern Inner Mongolia. In this region, the monthly average temperature is below $0^{\circ} \mathrm{C}$, and the animals are raised in a semi-extensive production system during severe winter. The grassland is completely covered with snow for approximately 200 days of the year, and therefore the grass-growing season is limited to five months per year. More details about the breeding history of Sanhe cattle can be found at: http://www.ansi.okstate.edu/breeds/cattle/sanhe. The most remarkable characteristic of Sanhe cattle is its adaptability to adverse environmental conditions wherein the temperature gets as low as $-50^{\circ} \mathrm{C}$. In addition, Sanhe cattle is well known for its disease resistance, hardiness, and survival under low-input and cold-stress conditions, high quality in both milk and meat production, and suitability for grazing.Although Sanhe cattle was challenged by high yield breeds, such as Holstein during the past 20 years, it still remains a major breed because of its high adaptability to harsh environmental conditions and high meat and milk yield (Wu et al., 2012). The characteristics of Sanhe cattle and the cold climatic conditions of grasslands in the northeastern Inner Mongolia in winter fulfilled the experimental conditions required for our study on the effects of severe cold stress on gene expression in cattle. The identification of differentially expressed genes (DEGs) might increase our understanding of the mechanisms underlying cold-stress response and allow the development of novel strategies for the breeding of animals that are more adapted to and perform well under extreme temperature conditions. Therefore, the objective of the present study was to systematically identify DEGs in the peripheral blood of Sanhe cattle in response to severe cold stress using the Affymetrix Bovine Genome Array.

\section{MATERIAL AND METHODS}

\section{Animals and blood samples}

Our study was performed on 30 healthy Sanhe heifers with similar genetic backgrounds, weight, and age in Xiertala Cattle Breeding Farm in Inner Mongolia, China. The cattle were semi-housed in the same cowshed and fed a total mixed ration. In order to induce cold stress, the cattle were transferred outdoor and were exposed to a temperature of $-32^{\circ} \mathrm{C}$ for $3 \mathrm{~h}$ followed by cowshed housing at $5^{\circ} \mathrm{C}$ for $15 \mathrm{~h}$. The experimental procedures were conducted in accordance with the management of a local farm in adverse winter conditions (Wu et al., 2012) and ethical approval was obtained from the Committee on Ethics of Animal

Genetics and Molecular Research 16 (2): gmr16029593 
Experimentation from the Beijing Jiaotong University. In order to detect the gene expression changes in response to cold stress, blood samples $(10 \mathrm{~mL})$ with EDTA were collected from each animal before and after the cold exposure. All blood samples were centrifuged for $10 \mathrm{~min}$ at $1,400 \mathrm{~g}$ and the peripheral blood mononuclear cells (PBMC) fractions consisting of $\mathrm{T}$ and B lymphocytes, NK cells, monocytes, neutrophils, basophils, and eosinophils were isolated carefully using the RNase-free pipette tips. This was followed by the immediate addition of $1.5 \mathrm{~mL}$ RNA fixer (Bioteke, Beijing, China), and the samples were stored at $-80^{\circ} \mathrm{C}$ for further analysis.

\section{RNA isolation of peripheral blood leukocytes}

Total RNA was isolated from $200 \mu \mathrm{L}$ white blood cells stored in RNA fixer at $-80^{\circ} \mathrm{C}$ using the TRIzol reagent (Invitrogen, Carlsbad, CA) according to the manufacturer's instructions. Subsequently, the total RNA was purified using an RNeasy kit (Qiagen, Valencia, CA) to remove any residual genomic DNA from the RNA sample. The total RNA was eluted in RNase-free water, quantified using the Nanodrop 2000 spectrophotometer (Thermo Scientific, Wilmington, DE), and the quality was assessed by using the Agilent 2100 Bioanalyzer (Agilent Technologies Inc, Santa Clara, CA). The samples that displayed a 260/280 ratio greater than 1.8 and the RNA integrity numbers greater than 8.0 were considered to have met the purity criteria.

\section{Microarray hybridization and data analysis}

Six RNA samples, three derived before and three after the cold exposure, were collected from three animals randomly selected from the 30 healthy heifers used for gene expression profiling in response to severe cold stress. Total RNA (100 ng) was used for the generation of double-stranded cDNA by T7 oligo (dT)-primed reverse transcription using a Eukaryotic Poly-A RNA Control kit (Affymetrix, Inc.). The biotin-labeled cRNA was generated using the custom MessageAmp ${ }^{\mathrm{TM}}$ II-Biotin aRNAAmplification Kit (Ambion, Austin, TX, USA). After purification, quantification, and fragmentation, the labeled cRNA was hybridized to the Affymetrix Bovine Genome Array (Affymetrix, Inc., Santa Clara, CA, USA). The GeneChip arrays were stained with streptavidin-phycoerythrin, washed at an Affymetrix Fluidics Station 450 (Affymetrix, Inc.), and scanned using the GeneChip Scanner 3000 (Affymetrix, Santa Clara, CA).

Hybridization raw data were generated using the GeneChip operating software (GCOS) and normalized according to the procedure of the Robust Multi-array Average (RMA) algorithm, which is a statistical method comprising three parts performed as follows: convolution background correction, probe-level quantile normalization, and median polish summarization for each probe set to estimate the $\log _{2}$ scale expression values (Irizarry et al., 2003). The identification of DEGs in cattle before and after the cold exposure was performed by a two-class paired method using the Significant Analysis of Microarray software (SAM). The significantly enriched pathways of DEGs were detected using the Ingenuity Pathway Analysis (IPA, http://www.ingenuity.com/) that provides computational algorithms to identify the most significant known biological pathways and generate gene networks that are particularly enriched with genes for a given set of genes (Nakatani et al., 2006). All analyzes were based on the annotation information from cattle databases. Furthermore, the list of DEGs was annotated using the DAVID tool (DAVID Bioinformatics Resources 6.7, National Institute of Allergy and Infectious Diseases, Huang da et al., 2009a,b).

Genetics and Molecular Research 16 (2): gmr16029593 


\section{Validation of gene expression using Real-Time qRT-PCR}

The real-time reverse transcriptase polymerase chain reaction analysis was used to confirm the mRNA expression data of genes identified by microarray. In brief, $1 \mu \mathrm{g}$ total RNA corresponding to each of the 30 samples, including the three samples used for microarray analysis, was reverse-transcribed in a $20-\mu \mathrm{L}$ final reaction mixture containing $4-\mu \mathrm{L} 5 \mathrm{X}$ firststrand buffer (250 mM Tris-HCl, $\mathrm{pH} 8.3 ; 375 \mathrm{mM} \mathrm{KCl} ; 15 \mathrm{mM} \mathrm{MgCl}$ ), $10 \mathrm{mM}$ DTT, 0.5 $\mathrm{mM}$ each dNTP, $40 \mathrm{U}$ RNaseOUT ${ }^{\mathrm{TM}}, 1-\mu \mathrm{L} 50 \mathrm{nM}$ random hexamers, and $200 \mathrm{U}$ Superscript II $\mathrm{RNase} \mathrm{H}^{-}$reverse transcriptase (Invitrogen).

The expression levels of 10 genes were investigated by qPCR, using the SYBR Select Master Mix (Applied Biosystems, Foster City, CA, USA) according to the manufacturer's instructions and observed by using the ABI Prism 7900HT sequence detection system (Applied Biosystems). The sequences for the primers were designed using Primer Premier 5.0 and are shown in Table 1. Amplification of $2 \mu \mathrm{L}$ of cDNA mixture was carried out in $20-\mu \mathrm{L}$ reaction volume. The standard PCR procedures were: activation at $5^{\circ} \mathrm{C}$ for $2 \mathrm{~min}$, initial denaturation at $95^{\circ} \mathrm{C}$ for $2 \mathrm{~min}$ followed by 40 cycles of denaturation at $95^{\circ} \mathrm{C}$ for $15 \mathrm{~s}$, and annealing at $60^{\circ} \mathrm{C}$ for $1 \mathrm{~min}$. The final gene expression level was normalized to the glyceraldehyde-3phosphate dehydrogenase $(G A P D H)$ gene, an internal control that exhibited little or no change in response to cold stress in our previous experiments. Each treatment was performed in triplicate or quadruplicate, and the data were analyzed with the comparative $C_{t}$ method (Winer et al., 1999) and normalized to GAPDH levels corresponding to each sample.

\begin{tabular}{|c|c|c|c|}
\hline Genes & Primer sequence (5' to $\left.3^{\prime}\right)$ & GenBank accession No. & Amplicon size (bp) \\
\hline \multirow[t]{2}{*}{ DGAT2 } & F: GTGGCCTCGCTTTGCTTAAC & \multirow[t]{2}{*}{ NM_205793.2 } & \multirow[t]{2}{*}{121} \\
\hline & R: TTGGGTTCGGGGAACTTCTG & & \\
\hline \multirow[t]{2}{*}{ FOS } & F: CGGGGACAGTCTCTCCTACT & \multirow[t]{2}{*}{ NM_182786.2 } & \multirow[t]{2}{*}{130} \\
\hline & R: GGCAGTCACTGTTGGGATGA & & \\
\hline \multirow[t]{2}{*}{$H P$} & F: CTGCAAGCTGTCGTCACTCT & \multirow[t]{2}{*}{ NM_001040470.2 } & \multirow[t]{2}{*}{116} \\
\hline & R:TCCACATGGCTATTAGCAATCTC & & \\
\hline \multirow[t]{2}{*}{ HSP70 } & F: CAGCCTGGAGAGAGCTGATAAAA & \multirow[t]{2}{*}{ NM_203322.2 } & \multirow[t]{2}{*}{135} \\
\hline & R: TCAAACCTGAAAACGGCCCA & & \\
\hline \multirow[t]{2}{*}{ KLFI1 } & F: AGGAGCCGAGAGAGAGGTTC & \multirow[t]{2}{*}{ XM_005213060.2 } & \multirow[t]{2}{*}{127} \\
\hline & R: GTCATGCCGTTTCCTCTCCA & & \\
\hline \multirow[t]{2}{*}{ MAPK1 } & F: AACAAAGTCCGAGTCGCCAT & \multirow[t]{2}{*}{ BC133588.1 } & \multirow[t]{2}{*}{148} \\
\hline & R: CGATGGTCGGTGCTCGAATA & & \\
\hline \multirow[t]{2}{*}{$L P L$} & F: CGGACTCCAACGTCATCGT & \multirow[t]{2}{*}{ NM_001075120.1 } & \multirow[t]{2}{*}{125} \\
\hline & R: TTCATCCGCCATCCAGTTC & & \\
\hline \multirow[t]{2}{*}{ KLHL28 } & F: TCTCCTTCCAGCAGCAAACC & \multirow[t]{2}{*}{ NM_001099030.1 } & \multirow[t]{2}{*}{129} \\
\hline & R: TGGCAACCATACGTCTCTGC & & \\
\hline \multirow[t]{2}{*}{ PTPN2 } & F: GAAAAGGCCAAGATTGACAGACA & \multirow[t]{2}{*}{ NM_001035431.2 } & \multirow[t]{2}{*}{150} \\
\hline & R: CACGTGAGGCAATCTATAGGCTTA & & \\
\hline \multirow[t]{2}{*}{$S D A D 1$} & F: ACCTGTTTGTAGGATGGGGC & \multirow[t]{2}{*}{ NM_001102489.1 } & \multirow[t]{2}{*}{129} \\
\hline & R: TGCAGAGTTGGTCTGTAAGGC & & \\
\hline \multirow[t]{2}{*}{$G A P D H$} & F: GGCGCCAAGAGGGTCAT & \multirow[t]{2}{*}{ NM_001034034.2 } & \multirow[t]{2}{*}{109} \\
\hline & R: AGGCATTGCTGACAATCTTGAG & & \\
\hline
\end{tabular}

\section{RESULTS}

\section{Changes in global gene expression caused by exposure to severe cold stress}

To identify and define severe cold stress-induced changes in gene expression, the expression profiling was conducted on peripheral blood samples obtained from Sanhe cattle 
before and after exposure to severe cold temperature. The cDNA microarray identified approximately 12,764 probe sets representing 10,053 genes in the six samples from Sanhe cattle. A total of 215 probes representing 193 UniGene numbers were found to exhibit significant and biologically meaningful changes in expression (fold change $\geq 1.3 ; \mathrm{P}<0.05$ ). Among the 193 genes associated with severe cold stress, 107 genes were up-regulated and 86 down-regulated. The datasets supporting above conclusions are available in the Gene Expression Omnibus (GEO) repository (unique persistent identifier: GSE79827, and hyperlink to datasets: http:// www.ncbi.nlm.nih.gov/geo/info/linking.html).

All 193 genes were successfully mapped to molecules in the Ingenuity Knowledge Base. The DEGs identified through the IPA procedure of Ingenuity and based on their functional annotation were significantly associated with 27 molecular and cellular functional categories (Figure 1), with the five most significant associations with the following categories: DNA replication, recombination, and repair (molecules: 10; $\mathrm{P}$ value: $2.47 \mathrm{E}^{-4}-3.17 \mathrm{E}^{-2}$ ); cell death and survival (molecules: 19; P value: $2.53 \mathrm{E}^{-4}-3.17 \mathrm{E}^{-2}$ ); cellular development (molecules: 28 ; $P$ value: $3.12 \mathrm{E}^{-4}-3.17 \mathrm{E}^{-2}$ ); cellular function and maintenance (molecules: 27 ; $\mathrm{P}$ value: $3.12 \mathrm{E}^{-4}$ -

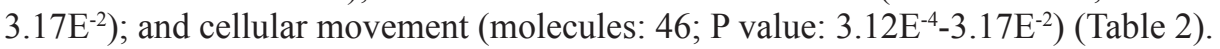

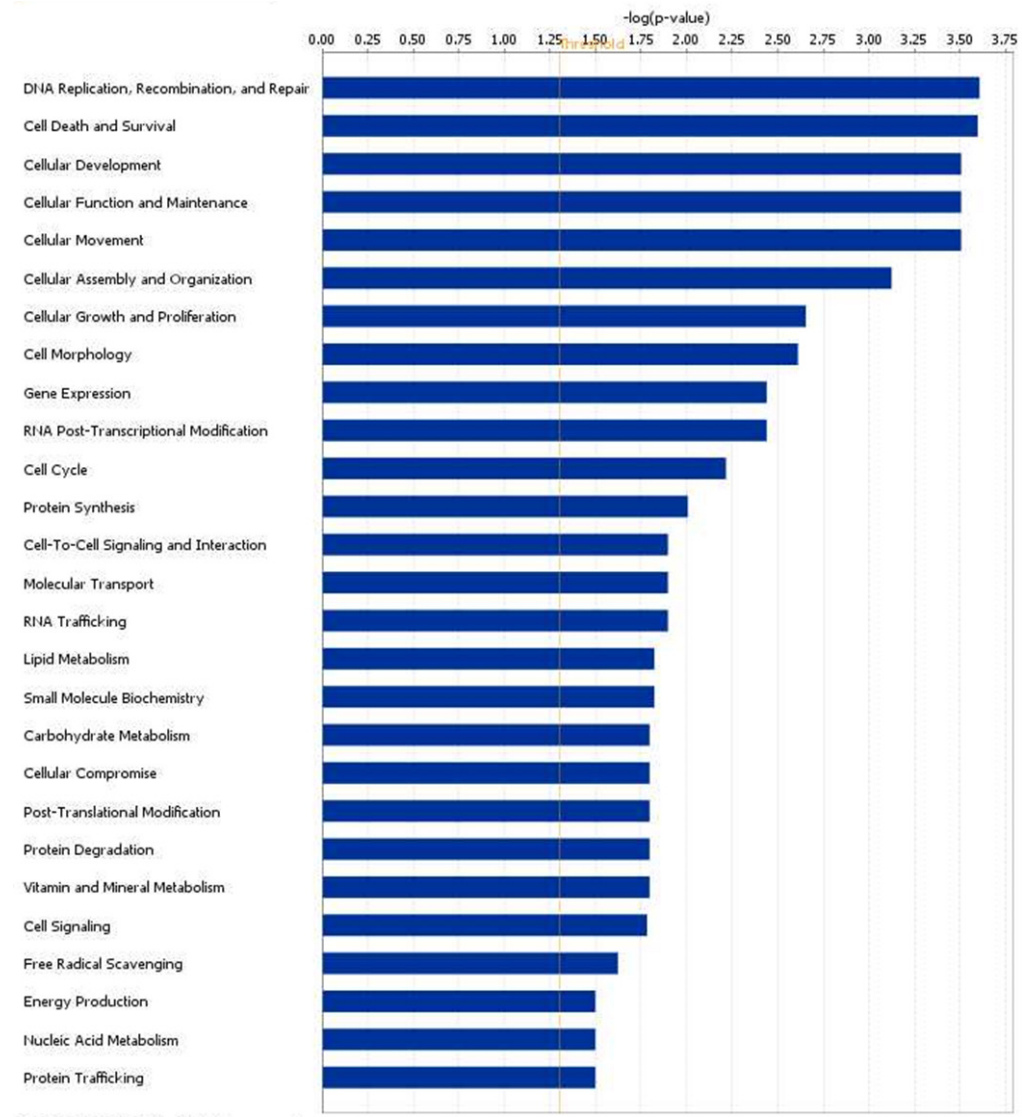

Figure 1. Molecular and cellular functional categories most significantly affected by differentially expressed genes after severe cold stress. The level of statistical significance is shown on the $\mathrm{x}$-axis. 
Table 2. Molecular and cellular functions identified by the IPA procedure.

\begin{tabular}{l|l|c}
\hline Category & \multicolumn{1}{|c}{ P value } & Molecules \\
\hline DNA Replication, Recombination, and Repair & $2.47 \mathrm{E}^{-4}-3.17 \mathrm{E}^{-2}$ & 10 \\
\hline Cell Death and Survival & $2.53 \mathrm{E}^{-4}-3.17 \mathrm{E}^{-2}$ & 28 \\
\hline Cellular Development & $3.12 \mathrm{E}^{-4}-3.17 \mathrm{E}^{-2}$ & 27 \\
\hline Cellular Function and Maintenance & $3.12 \mathrm{E}^{-4}-3.17 \mathrm{E}^{-2}$ & 46 \\
\hline Cellular Movement & $3.12 \mathrm{E}^{-4}-3.17 \mathrm{E}^{-2}$ & 16 \\
\hline Cellular Assembly and Organization & $7.50 \mathrm{E}^{-4}-3.17 \mathrm{E}^{-2}$ & 17 \\
\hline Cellular Growth and Proliferation & $2.22 \mathrm{E}^{-3}-3.17 \mathrm{E}^{-2}$ & 5 \\
\hline Cell Morphology & $2.45 \mathrm{E}^{-3}-3.17 \mathrm{E}^{-2}$ & 2 \\
\hline Gene Express & $3.64 \mathrm{E}^{-3}-1.60 \mathrm{E}^{-2}$ & 15 \\
\hline RNA Post-Transcription Modification & $3.64 \mathrm{E}^{-3}-3.64 \mathrm{E}^{-3}$ & 14 \\
\hline Cell Cycle & $6.08 \mathrm{E}^{-3}-3.17 \mathrm{E}^{-2}$ & \\
\hline Protein Synthesis & $9.84 \mathrm{E}^{-3}-2.90 \mathrm{E}^{-2}$ & \\
\hline
\end{tabular}

\section{Pathways and networks associated with severe cold stress}

Canonical molecular pathways associated with severe cold stress were analyzed using the IPA defined at $\mathrm{P}<0.05$ and IPA significance value $>1.3$. These canonical pathways were ranked according to the IPA significance value, which represents the significance of an association between a specific pathway and genes in the input data set. Analysis of the IPA-identified canonical pathways indicates that the majority of the most highly correlated pathways mediated cellular immune response, cellular development and growth, cellular stress and injury, and lipid metabolism. As shown in Table 3, the eight top ranking pathways included IL-10 signaling (four genes up-regulated), EIF2 signaling (two up-regulated and four down-regulated genes), Gai signaling (three up-regulated and one down-regulated gene), GDNF family ligand-receptor interactions (three up-regulated genes), neurotropic/ TRK signaling (three up-regulated genes), IL-17A signaling in gastric cells (two up-regulated genes), LXR/RXR activation (two up-regulated and two down-regulated genes), and VEGF family ligand-receptor interactions (three up-regulated genes). Using the DAVID tool, the MAPK signaling pathway and endocytosis were also identified as the pathways containing an overrepresentation of DEGs, wherein a cold exposure increased the expression of all nine genes. In particular, the alterations in the FOS and MAPK1 (both up-regulated by cold exposure) genes that are involved in several pathways, highlighted their potential functional importance in the cold-stress response in cattle. These findings provide evidence that the above pathways play important roles in the generation of cold-stress response in cattle.

Table 3. Pathways identified by IPA procedure or KEGG.

\begin{tabular}{|c|c|c|}
\hline Ingenuity canonical pathways & $\mathrm{P}$ value & Genes* \\
\hline IL-10 Signaling & $2.3 \mathrm{E}^{-3}$ & FOS, MAPK1, IL1R1, FCGR2B \\
\hline EIF2 Signaling & $2.1 \mathrm{E}^{-2}$ & MAPK1, RPS18, EIF2B1, RPLP2, RPL7L1, EIF2S3 \\
\hline Gai Signaling & $3.0 \mathrm{E}^{-2}$ & P2RY13, MAPK1, CNR2, SIPR1 \\
\hline GDNF Family Ligand-Receptor Interactions & $3.5 \mathrm{E}^{-2}$ & $F O S, M A P K 1, D O K 1$ \\
\hline Neurotrophin /TPR Signaling & $3.6 \mathrm{E}^{-2}$ & FOS, MAPK1, SPRY2 \\
\hline IL-17A Signaling in Gastric Cells & $4.2 \mathrm{E}^{-2}$ & FOS, MAPK1 \\
\hline LXR/RXR Activation & $4.3 \mathrm{E}^{-2}$ & $L Y Z, M S R 1, L P L, I L 1 R 1$ \\
\hline VEGF Family Ligand-Receptor Interactions & $4.6 \mathrm{E}^{-2}$ & FOS, NPR2, MAPKI \\
\hline \multicolumn{3}{|l|}{ KEGG pathways } \\
\hline MAPK signaling pathway & $4.4 \mathrm{E}^{-4}$ & DUSP10, HSPA1A, HSPA2, HSPB8, ILIR1, MAPK1, FOS \\
\hline Endocytosis & $1.7 \mathrm{E}^{-2}$ & $A C A P 1, C H M P 4 B, H S P A 1 A, H S P A 2, H S P B 8$ \\
\hline
\end{tabular}

*Genes up-regulated by cold stress are shown in normal and down-regulated genes are shown in bold.

Genetics and Molecular Research 16 (2): gmr16029593 
The IPA network analysis identified 13 biological networks with a score value of more than 10 (Table 4). The top three functional networks had more than 40 genes, including ANKRD34A, GDPD1, HP, LPL, MAPK1, MAPK6, NITI, P2RY13, and RPE. The functional annotation of all networks showed that the top canonical functions associated with these 13 networks are cellular compromise, cellular movement, lipid metabolism, molecular transport, cell death, and survival. Not surprisingly, many of these pathways are also known to be important in stress response. It is important to point out that three networks shared one common gene, ubiquitin $\mathrm{C}(U B C)$. In Figure 2, all genes encoding the proteins that interact with UBC are shown, with different shapes of the nodes indicating the "family" of a given gene assigned using the IPA annotations and the color of the node indicating the presence (red or green) or absence (white) of a given gene in the study. Nodes that are not represented in the study (white nodes) were retained in the network for a context-dependent view of the functional interactome. A total of 45 differentially regulated genes ( $23 \%$ of the DEGs available for analysis) in these three networks were associated with UBC. These genes included the molecules that bind to UBC ( 25 genes up-regulated and 19 down-regulated by cold stress) as well as the molecules that interact with a UBC-binding molecule. These results suggest that UBC might influence multiple functional networks via interaction with other genes. Further studies are required to understand the role of this gene in the pathophysiology of cold stress.

Table 4. Biological network identified by Ingenuity Pathway Analysis (IPA) procedure.

\begin{tabular}{|c|c|c|}
\hline Associated function network & Gene hits & Score \\
\hline Cellular Compromise, Cellular Movement, Hematological System Development and Function & 18 & 31 \\
\hline Lipid Metabolism, Molecular Transport, Small Molecular Biochemistry & 17 & 29 \\
\hline Cell Cycle, Cellular Assembly and Organization, DNA Replication, Recombination, and Repair & 17 & 29 \\
\hline Tissue Morphology, Cancer & 18 & 28 \\
\hline Cellular Assembly and Organization, Cellular Function and Maintenance, Cell Cycle & 16 & 26 \\
\hline Cellular Development, Embryonic Development, Organismal Development & 16 & 25 \\
\hline RNA Post-Transcription Modification, Cell Cycle, Developmental Disorder & 15 & 24 \\
\hline Molecular Transport, Small Molecular Biochemistry & 15 & 24 \\
\hline DNA Replication, Recombination, and Repair, Cell Cycle, Cellular Development & 15 & 22 \\
\hline Cell Death and Survival, Nervous System & 14 & 21 \\
\hline Embryonic Development, Organismal Development, Tissue Development, & 12 & 18 \\
\hline Humoral Immune Response, Protein Synthesis, Cell Death and Survival & 10 & 14 \\
\hline Cellular Movement, Connective Tissue Development and function, Cell Signaling & 9 & 12 \\
\hline
\end{tabular}

\section{Validation of gene expression data by real-time qRT-PCR}

In order to independently validate the cold stress-induced gene expression changes in the peripheral blood of Sanhe cattle, 10 differentially expressed genes detected in our microarray study were selected for the qRT-PCR analysis. qRT-PCR was conducted for all 30 samples, including the three RNA samples used in microarray study. Six of the 10 genes analyzed using the real-time qRT-PCR (DGAT2, FOS, HP, HSP70, KLF11, and MAPK1) showed a significant increase in their expression $(\mathrm{P}<0.05)$, and four genes $(L P L, K L H L 28, P T P N 2$, and SDAD1) displayed a significant decrease in their expression $(\mathrm{P}<0.05)$ on exposure to cold stress. Gene expression profiles for these 10 genes were in accordance with the microarray results. However, some differences were observed in the levels of gene expression detected by the two methods. For example, HSP70 showed a +1.82 -fold increase in its relative expression based on the real-time qRT-PCR results, but displayed +1.51 -fold increase according to the microarray results. The observed differences between the microarray and real-time qRT-PCR

Genetics and Molecular Research 16 (2): gmr16029593 
data might be due to the differences in the sensitivity of the two methods used, the mRNA transcripts targeted by the probes (microarray) and primer pairs (real-time qRT-PCR), or the number of samples tested by each method (three samples in microarray, 30 samples in realtime qRT-PCR) (Table 5).

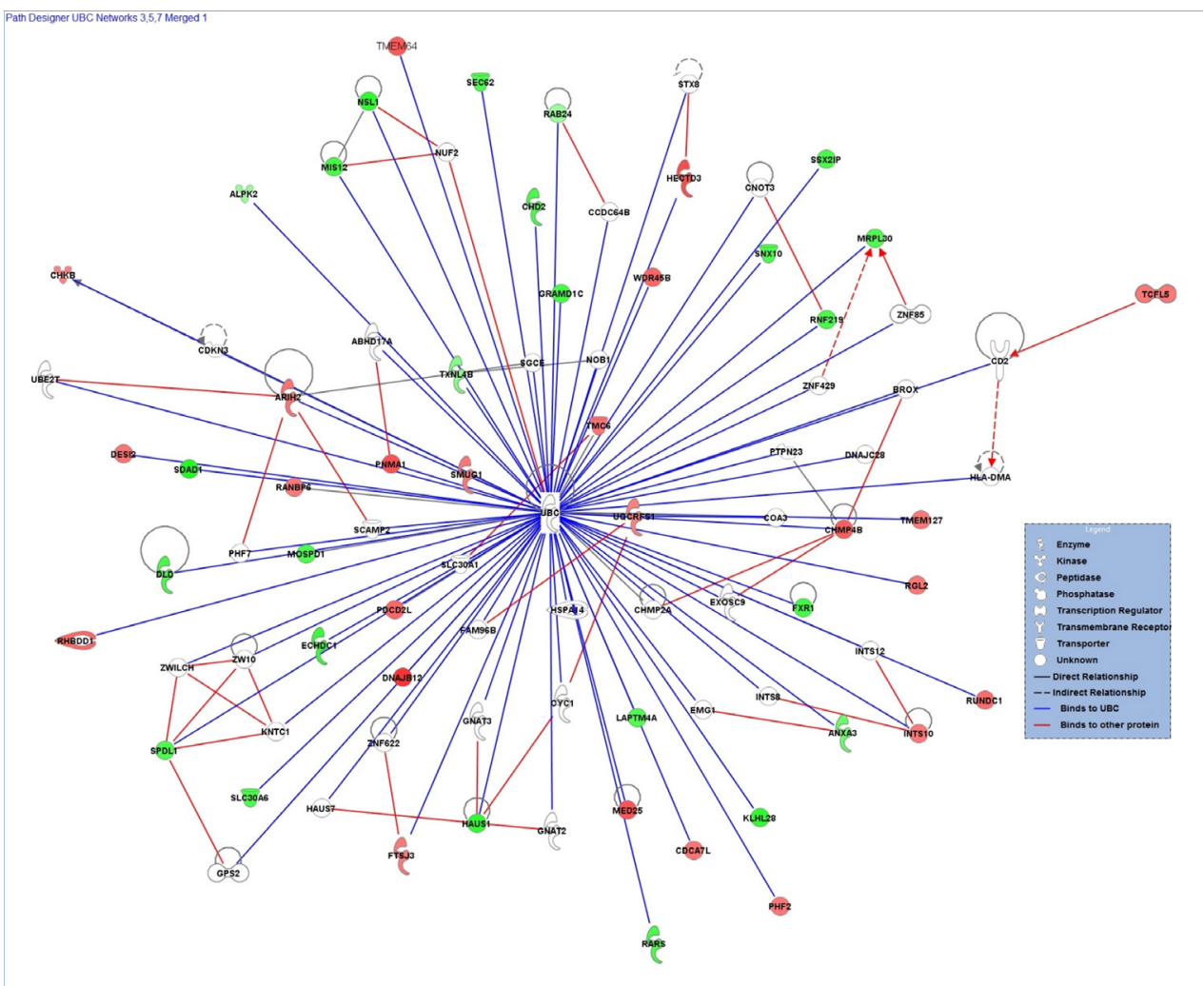

Figure 2. Genes encoding for proteins that interact with ubiquitin $\mathrm{C}$ (UBC). Genes up-regulated and downregulated by severe cold stress are shown in red and green colors, respectively. The binding with UBC is denoted by blue lines, whereas the binding between other proteins is shown by pink lines. Other relationships are marked by arrows. Data were generated with IPA software.

Table 5. Comparison of microarray and qPCR analyses.

\begin{tabular}{l|c|c|c|c}
\hline \multirow{2}{*}{ Gene } & \multicolumn{2}{|c|}{ Fold change (after cold/before cold) } & \multicolumn{2}{c}{ P value } \\
\cline { 2 - 5 } & Microarray & qPCR & Microarray & qPCR \\
\hline DGAT2 & 1.64 & 1.83 & 0.03 & 0.03 \\
\hline FOS & 1.52 & 1.69 & 0.04 & 0.00 \\
\hline HP & 1.72 & 2.30 & 0.04 & 0.01 \\
\hline HSPA1A & 1.51 & 1.82 & 0.05 & 0.02 \\
\hline KLF11 & 1.68 & 2.05 & 0.02 & 0.03 \\
\hline LPL & 1.45 & 1.68 & 0.05 & 0.01 \\
\hline KLHL28 & -1.98 & -1.84 & 0.04 & 0.04 \\
\hline PTPN2 & -2.18 & -2.04 & 0.02 & 0.00 \\
\hline SDAD1 & -1.87 & -2.32 & 0.03 & 0.01 \\
\hline
\end{tabular}

Genetics and Molecular Research 16 (2): gmr16029593 


\section{DISCUSSION}

While there is a large volume of literature published on cold-stress response in plants (e.g., Barah et al., 2013; Sharma and Nayyar, 2014), the response of animals to cold stress and the molecular mechanisms underlying animals' responses to cold stress are still unknown. It is evident that the cold-stress response in eukaryotic cells involves a coordinated series of responses involving the modulation of cell cycle, metabolism, transcription, translation, and cell cytoskeleton (Al-Fageeh and Smales, 2006). In mammals, a cold exposure imposes a metabolic challenge leading to a coordinated response in different tissues to prevent hypothermia.

To our knowledge, severe cold stress has never been reported in cattle. In this study, we provide the first molecular evidence of the differences in the transcripts expression pattern in Sanhe cattle exposed to severe cold stress at $-32^{\circ} \mathrm{C}$ for $3 \mathrm{~h}$. The qRT-PCR analysis for evaluation of the gene expression corresponded well with the microarray gene expression analysis. We found that the expression levels of a total of 193 genes were affected by the severe cold stress. By enrichment analysis of pathways and functional networks associated with these cold regulated genes, the main molecular and cellular functions that were affected in cold stress were DNA replication, recombination and repair, cell death and survival, cellular development, cellular function and maintenance, and cellular movement. Furthermore, the most highly correlated pathways and networks were cellular immune response, cellular development and growth, cellular stress and injury, and lipid metabolism. These results provide insights into the molecular basis of severe cold stress in cattle. Similar molecular and cellular functions in response to cold stress have been previously reported in other animal species. For example, a transcriptomic analysis of brown adipose tissue, white adipose, and liver of the mice exposed to cold stress at $8^{\circ} \mathrm{C}$ for $24 \mathrm{~h}$ revealed that the 1,895 genes regulated by cold exposure were involved in the oxidoreductase activity, lipid metabolic processes, and protease inhibitor activity (Shore et al., 2013). In cold-stressed broilers, the expression of 30 genes in the pituitary gland were found to be differentially regulated, and the majority of these genes were related to enzyme and metabolism, cell development, apoptosis, and some signaling pathways (Chen et al., 2012).

We confirmed the cold stress-induced changes in the expression of 193 genes in the PBMCs of Sanhe cattle by real-time qRT-PCR. Among other changes, particularly notable were the up-regulation of FOS and MAPK1. Considering the involvement of FOS and MAPK1 in several pathways, such as IL-10 signaling, $G D N F$ family ligand-receptor interactions, and $M A P K$ signaling pathway, they might play functionally important roles in generating the coldstress responses in cattle. In agreement with these results, other $M A P K$ pathway components have also been reported to exhibit significant changes in response to cold stress. In yeast, when the temperature is decreased to $12^{\circ}$ or $4^{\circ} \mathrm{C}$, the Hog pathway is known to get activated via the activation and phosphorylation of MAPK HOG1P (Panadero et al., 2006). In mammalian cells, the phosphorylation of $\mathrm{p} 38 M A P K$ upon cold stimulation might lead to their recovery from cold shock (Gon et al., 1998). Further, the phosphorylation of $J N K$ was reportedly increased upon cold shock and then increased further upon rewarming (Ohsaka et al., 2002). In Arabidopsis plants, the overexpression of NPK1 resulted in the activation of oxidative stress-responsive genes and increased tolerance of the transgenic plants to freezing, salt, and heat stress (Kovtun et al., 2000). In the current study, we observed an increase in the MAPK1 expression following cold exposure, and IPA indicated the involvement of $M A P K$ signaling pathway, thus suggesting $M A P K 1$ to be a new candidate gene for studies on cold stress in animals.

Genetics and Molecular Research 16 (2): gmr16029593 
Further, we were interested in the cold-induced changes in heat shock proteins (HSPs). HSPs are a family of ubiquitous, highly conserved stress proteins that are expressed in all organisms, from bacteria to humans (Lindquist and Craig, 1988). HSPs act as molecular chaperones for other cellular proteins involved in a variety of functions such as protein folding, protein transport and assembly, and protein degradation (Ellis and van der Vies, 1991; Parsell and Lindquist, 1993). Researchers have demonstrated that HSPs play important physiological roles under normal conditions and situations involving both systemic and cellular stresses. Most HSPs have strong cytoprotective effects and are involved in many regulatory pathways related to cell stress response (Moseley, 1997). Other studies have investigated the effects of cold exposure on expression of HSPs in different cell types, and the expression of HSP25, HSP70, HSP72, HSP89, HSP90, and HSP98 have been reported to increase during cold exposure or after recovery (Fujita, 1999). However, the effects of cold stress on HSPs are highly variable, varying from induction to suppression, depending on the cell types, cell cycle status, and temperature (Hatayama et al., 1992). Among the 27 genes, including HSPs, heat shock transcription factors, or HSP-binding proteins, only HSPA1A expression was found to be up-regulated in the present study $(\mathrm{P}<0.05)$. In line with the present study, another study evaluated the expression pattern of the $H S P 70$-family genes in different ruminant breeds with respect to different seasons. An increased expression of the HSP70-family genes was observed in buffaloes during the winter season. According to Kumar et al. (2015), variations in the expression pattern of the $H S P 70$-family genes during different seasons might be associated with the better adaptability of Indian zebu cattle to different climatic conditions. Our findings offer new insights on the possible molecular mechanisms underlying cold-stress response in cattle. Further characterization of the genes differentially expressed in response to cold stress might lead to the identification of novel blood biomarkers that could be used to assess the ability of cattle to resist/tolerate extremely cold climatic conditions. Future studies, including other cattle breeds and yaks, will be performed to investigate the signatures of selection and to identify new candidate genes related to severe cold-stress response in cattle.

\section{Conflicts of interests}

The authors declare no conflict of interest.

\section{ACKNOWLEDGMENTS}

Research supported by the National Natural Science Foundation of China Project (\#31172191), the earmarked fund for Modern Agro-industry Technology Research System (\#CARS-37), and the Program for Changjiang Scholar and Innovation Research Team in University (\#IRT1191).

\section{REFERENCES}

Al-Fageeh MB and Smales CM (2006). Control and regulation of the cellular responses to cold shock: the responses in yeast and mammalian systems. Biochem. J. 397: 247-259. https://doi.org/10.1042/BJ20060166

Angrecka S and Herbut P (2015). Conditions for cold stress development in dairy cattle kept in free stall barn during severe frosts. Czech J. Anim. Sci. 60: 81-87. https://doi.org/10.17221/7978-CJAS

Azzam SM, Kinder JE, Nielsen MK, Werth LA, et al. (1993). Environmental effects on neonatal mortality of beef calves. J. Anim. Sci. 71: 282-290.

Genetics and Molecular Research 16 (2): gmr16029593 
Barah P, Jayavelu ND, Rasmussen S, Nielsen HB, et al. (2013). Genome-scale cold stress response regulatory networks in ten Arabidopsis thaliana ecotypes. BMC Genomics 14: 722. https://doi.org/10.1186/1471-2164-14-722

Broucek J, Letkovicová M and Kovalcuj K (1991). Estimation of cold stress effect on dairy cows. Int. J. Biometeorol. 35: 29-32. https://doi.org/10.1007/BF01040960

Chebel RC, Braga FA and Dalton JC (2007). Factors affecting reproductive performance of Holstein heifers. Anim. Reprod. Sci. 101: 208-224. https://doi.org/10.1016/j.anireprosci.2006.09.010

Chen X, Jiang R and Geng Z (2012). Cold stress in broiler: global gene expression analyses suggest a major role of CYP genes in cold responses. Mol. Biol. Rep. 39: 425-429. https://doi.org/10.1007/s11033-011-0754-X

Cheng P (1984). Livestock breeds of China. Animal Production and Health Paper 46 (E, F, S). FAO, Rome, 217.

Collier RJ, Collier JL, Rhoads RP and Baumgard LH (2008). Invited review: genes involved in the bovine heat stress response. J. Dairy Sci. 91: 445-454. https://doi.org/10.3168/jds.2007-0540

Ellis RJ and van der Vies SM (1991). Molecular chaperones. Annu. Rev. Biochem. 60: 321-347. https://doi.org/10.1146/ annurev.bi.60.070191.001541

Fujita J (1999). Cold shock response in mammalian cells. J. Mol. Microbiol. Biotechnol. 1: 243-255.

Gon Y, Hashimoto S, Matsumoto K, Nakayama T, et al. (1998). Cooling and rewarming-induced IL-8 expression in human bronchial epithelial cells through p38 MAP kinase-dependent pathway. Biochem. Biophys. Res. Commun. 249: 156160. https://doi.org/10.1006/bbrc.1998.9115

Hatayama T, Tsujioka K, Wakatsuki T, Kitamura T, et al. (1992). Effects of low culture temperature on the induction of hsp70 mRNA and the accumulation of hsp70 and hsp105 in mouse FM3A cells. J. Biochem. 111: 484-490. https:// doi.org/10.1093/oxfordjournals.jbchem.a123784

Hu H, Zhang Y, Zheng N, Cheng J, et al. (2016). The effect of heat stress on gene expression and synthesis of heat-shock and milk proteins in bovine mammary epithelial cells. Anim. Sci. J. 87: 84-91. https://doi.org/10.1111/asj.12375

Huang W, Sherman BT and Lempicki RA (2009a). Bioinformatics enrichment tools: paths toward the comprehensive functional analysis of large gene lists. Nucleic Acids Res. 37: 1-13. https://doi.org/10.1093/nar/gkn923

Huang W, Sherman BT and Lempicki RA (2009b). Systematic and integrative analysis of large gene lists using DAVID bioinformatics resources. Nat. Protoc. 4: 44-57. https://doi.org/10.1038/nprot.2008.211

Irizarry RA, Hobbs B, Collin F, Beazer-Barclay YD, et al. (2003). Exploration, normalization, and summaries of high density oligonucleotide array probe level data. Biostatistics 4: 249-264. https://doi.org/10.1093/biostatistics/4.2.249

Kovtun Y, Chiu WL, Tena G and Sheen J (2000). Functional analysis of oxidative stress-activated mitogen-activated protein kinase cascade in plants. Proc. Natl. Acad. Sci. USA 97: 2940-2945. https://doi.org/10.1073/pnas.97.6.2940

Kumar A, Ashraf S, Goud TS, Grewal A, et al. (2015). Expression profiling of major heat shock protein genes during different seasons in cattle (Bos indicus) and buffalo (Bubalus bubalis) under tropical climatic condition. J. Therm. Biol. 51: 55-64. https://doi.org/10.1016/j.jtherbio.2015.03.006

Lindquist S and Craig EA (1988). The heat-shock proteins. Annu. Rev. Genet. 22: 631-677. https://doi.org/10.1146/ annurev.ge.22.120188.003215

Moseley PL (1997). Heat shock proteins and heat adaptation of the whole organism. J. Appl. Physiol. (1985) 83: 1413-1417.

Nakatani N, Hattori E, Ohnishi T, Dean B, et al. (2006). Genome-wide expression analysis detects eight genes with robust alterations specific to bipolar I disorder: relevance to neuronal network perturbation. Hum. Mol. Genet. 15: 19491962. https://doi.org/10.1093/hmg/dd1118

Ohsaka Y, Ohgiya S, Hoshino T and Ishizaki K (2002). Phosphorylation of c-Jun N-terminal kinase in human hepatoblastoma cells is transiently increased by cold exposure and further enhanced by subsequent warm incubation of the cells. Cell. Physiol. Biochem. 12: 111-118. https://doi.org/10.1159/000063787

Panadero J, Pallotti C, Rodríguez-Vargas S, Randez-Gil F, et al. (2006). A downshift in temperature activates the high osmolarity glycerol (HOG) pathway, which determines freeze tolerance in Saccharomyces cerevisiae. J. Biol. Chem. 281: 4638-4645. https://doi.org/10.1074/jbc.M512736200

Parsell DA and Lindquist S (1993). The function of heat-shock proteins in stress tolerance: degradation and reactivation of damaged proteins. Annu. Rev. Genet. 27: 437-496. https://doi.org/10.1146/annurev.ge.27.120193.002253

Sharma KD and Nayyar H (2014). Cold stress alters transcription in meiotic anthers of cold tolerant chickpea (Cicer arietinum L.). BMC Res. Notes 7: 717. https://doi.org/10.1186/1756-0500-7-717

Shore AM, Karamitri A, Kemp P, Speakman JR, et al. (2013). Cold-induced changes in gene expression in brown adipose tissue, white adipose tissue and liver. PLoS One 8: e68933. https://doi.org/10.1371/journal.pone.0068933

Sonna LA, Kuhlmeier MM, Khatri P, Chen D, et al. (2010). A microarray analysis of the effects of moderate hypothermia and rewarming on gene expression by human hepatocytes (HepG2). Cell Stress Chaperones 15: 687-702. https://doi. org/10.1007/s12192-010-0181-2

West JW (2003). Effects of heat-stress on production in dairy cattle. J. Dairy Sci. 86: 2131-2144. https://doi.org/10.3168/

Genetics and Molecular Research 16 (2): gmr16029593 
jds.S0022-0302(03)73803-X

Winer J, Jung CK, Shackel I and Williams PM (1999). Development and validation of real-time quantitative reverse transcriptase-polymerase chain reaction for monitoring gene expression in cardiac myocytes in vitro. Anal. Biochem. 270: 41-49. https://doi.org/10.1006/abio.1999.4085

Wu H, Ma X, Liu A, Liu Y, et al. (2012). Breeding history and current improvements of Sanhe Cattle in Inner Mongolia. China Cattle Sci. 38: 48-52. 